CRORR 9 (2018), 11-24

\title{
GIS-based Decision Support Concept to planning of land acquisition for realization of Urban Public Projects
}

\author{
Jelena Kilic ${ }^{1, *}$, Nikša Jajac ${ }^{1}$ and Ivan Marović ${ }^{2}$ \\ ${ }^{1}$ Faculty of Civil Engineering, Architecture and Geodesy, University of Split, \\ Matice hrvatske 15, 21000 Split, Croatia \\ E-mail: <\{jkilic,njajac\}@gradst.hr> \\ ${ }^{2}$ Faculty of Civil Engineering, University of Rijeka, \\ Ulica Radmile Matejčić 3, 51000 Rijeka, Croatia \\ E-mail: <ivan.marovic@uniri.hr>
}

\begin{abstract}
Planning of the land acquisition is a complex task and integral part of the planning phase within management of large scale construction projects especially of public projects in urban areas. This paper describes research on the establishment of GIS-based Decision Support Concept (DSC) to planning of land acquisition for realization of urban public projects that can be useful to project managers. It is focused on establishment of concept that supports identification, selection and priority ranking of spatial units whose acquisition enables further realization of commenced project. The complexity of such task arises from the dynamics of the project and its subprojects, a large number of diverse spatial and other data to be taken into account, several stakeholders groups with different opinions (providing diverse and often conflicting criteria to evaluate alternative spatial units). The concept is based on the SDSS logic and multicriteria analysis. Applying a family of PROMETHEE Methods and AHP Method comparison of selected spatial units according to priority for acquisition is provided in a form of priority ranking list. Insights obtained by analysis of these results as well as other influential factors (such as strategies and plans of a higher order, active contracts, etc.) are then used as the basis for design of additional spatialfunctional constrains by decision-maker introduced trough PROMETHEE V Method which ensured definition of the first acquisition's implementation phase defining a set of spatial units that are recommended for acquisition within next investment/project cycle. The proposed concept was tested on planning of land acquisition for realization of the University Campus Project in Split, Croatia.
\end{abstract}

Keywords: land acquisition, project management, multicriteria decision making, PROMETHEE, AHP

Received: October 5, 2016; accepted: March 22, 2018; available online: July 24, 2018

DOI: $10.17535 /$ crorr.2018.0002

\footnotetext{
${ }^{*}$ Corresponding author. 


\section{Introduction}

Researching the management of large scale construction projects, especially the part that refers to its spatial aspects in urban areas, a number of absences have been observed. This paper will focus on research problem of large quantity of different spatial and other type of data needed for planning of land acquisition, as well as the possibilities and ways of processing these data in order to create a better base for decision-making. Converting spatial data into information about the spatial aspects, the base in order to support project management will be created. The aim is to model the GIS-based Decision Support Concept (DSC) to planning of land acquisition for realization of urban public projects. DSC will advance the quality of decisionmaking process and will present the organization (structuring) and the use of spatial data for the purpose of improving the processes in managerial decision making. The concept is based on the DSS logic and multicriteria analysis. According to the subject of research which is based on spatial data, spatial decision support system (SDSS) logic will be used also. SDSS provides support to decision-making of land use where there are geographical or spatial component in the decision-making process [9]. It is designed to help decision-maker (investor or its representative - project manager) during the spatial planning of land use. SDSS is a relatively new field developed based on Geographic Information System (GIS) and Decision Support System (DSS) [10]. Many spatial problems require inclusion of multiple stakeholders with their different preferences and knowledges, political agendas and social interests. Making decisions is a synergistic action between multiple stakeholders in solving specific problems [7].

The concept which will be introduced in this paper is supported by many reasons, such as: the dynamics of the project and its subprojects, a large number of diverse spatial and other data to be taken into account (such as location, ownership, area of spatial units etc.), a number of possible solutions, the size and diversity of the analysed aspects of the problem (investment, construction and socio-real estate market aspects) which should be taken into consideration, several stakeholders groups with different opinions (providing diverse and often conflicting criteria to evaluate alternative spatial units). This indicates the different types of data by the units of measurement in which are expressed and the manner of their expression, whether they are described numerically or descriptively. The decision making process is characterized with evaluation of spatial units by seemingly incomparable criteria. The concept will be grounded on applying Preference Ranking Organization Method for Enrichment Evaluation - PROMETHEE [1] and Analytic Hierarchy Process - AHP [11] multicriteria methods which will be used to compare the set of spatial units. Multicriteria methods will appear in the model base and will be used as the basic approach to generating priority ranking of spatial units (cadastral parcels or their segments) whose acquisition enables further realization of commenced project. Combination of abovementioned methods in a such way as it is presented below can be found in previous papers of co-authors of this paper as results in researching slightly different scientific subjects but related to project management in a field of civil engineering and realestate. Jajac et al. in their papers have been deal with: [3] introducing multicriteria methods to maintenance planning of investments in urban infrastructure projects, [2] presenting how multicriteria methods can be implemented in choice of best location for construction site, [4] presenting DSC for managing the maintenance of city parking facilities, [5] using multicriteria 
methods for planning the maintenance of road infrastructure and [6] using DCS for selection of the method for rehabilitation of historic bridges.

\section{Description of Decision Support Concept (DSC) to planning of land acquisition for realization of Urban Public Projects}

Figure 1 shows architecture of generic concept to planning of the land acquisition for urban public projects realization. Application of the concept begins with identification and gathering together all stakeholders by investor (within Figure 1 investors activities are rounded with solid line and it is not coloured). Stakeholders are divided into four groups: investor (or its representative - project manager), government representative, private owners of parcels representatives and users' representatives. The first step is analysis of investment project by project manager which includes analysis of spatial unit area, analysis of project components, analysis of other relevant influences and analysis of stakeholders. In the next step all identified, selected and grouped stakeholders simultaneously are performing two activities (activities of all stakeholders are marked with solid lines and they are grey coloured). Their first activity is to design goal hierarchy structure that consists of the main goal, its objectives and the criteria. At the top of hierarchy is the main goal and it is divided into several supporting objectives (subgoals that supports the main goal). Realization of all objectives implies the realisation of the main goal. All stakeholders are involved in the process of goal tree design. While dividing each objective into criteria, representative of the stakeholder group which is relevant for that aspect is in charge. Decisions on inclusion of generated/identified criteria (by all stakeholder representatives) in goal tree is achieved by consensus. The second activity is spatial analysis of the project area which includes identification of relevant spatial units for acquisition and definition of spatial units set that will be used in further steps of the concept implementation. Next step is evaluation of defined spatial units by all criteria and selection of adequate muticriteria method for their comparison. Comparison must be based on harmonized opinion of all stakeholders which is expressed by criteria weights and selected preference functions. Determination of criteria weights is performing by AHP method. Comparison of alternatives by PROMETHEE II method results in their priority ranking for inclusion in the acquisition plan.

However, the best ranked alternative should not be selected as acquisition plan solution. This is due the number of influences related to the acquisition planning which need to be explored before final definition of acquisition plan. Those influences are related to opinion of investor (about acquisition planning) which is not covered by criteria such as availability of required resources (especially financial resources), strategies and plans of a higher order, active contracts, etc. Therefore, it is necessary to define and introduce several constrains which can cover all relevant influences. The constrains are then introduced using PROMETHEE $\mathrm{V}$ Method (combination of PROMETHEE II method and (0-1) linear programming) which ensured defining 1st set of spatial units to be acquired. After 1st set defining, the process is repeated but now is using the rest of spatial units that were identified within analysis of construction area. The cycle is conducting until all spatial units are acquired. Repetition of priority ranging ranking and selection of subsets of spatial units is recommended due constant 
changing of project environment. That way refreshing of all input data for the proposed concept and consequently of its results is ensured.

\section{DSC validation - Planning of "Campus" project}

Planning of the land acquisition is a complex task and integral part of the planning phase within management of large scale construction projects (projects which are consisted of several subprojects) especially of public projects in urban areas. A larger number of stakeholders in these projects further contributes the complexity of public projects. Large scale construction projects management requires decision making of a large number of stakeholders various views based on numerous diverse spatial data. That case is the construction project of the University Campus in Split (where University of Split is investor) in which the acquisition planning of spatial units will be support by the use of the proposed DSC, and with which the concept is validated.

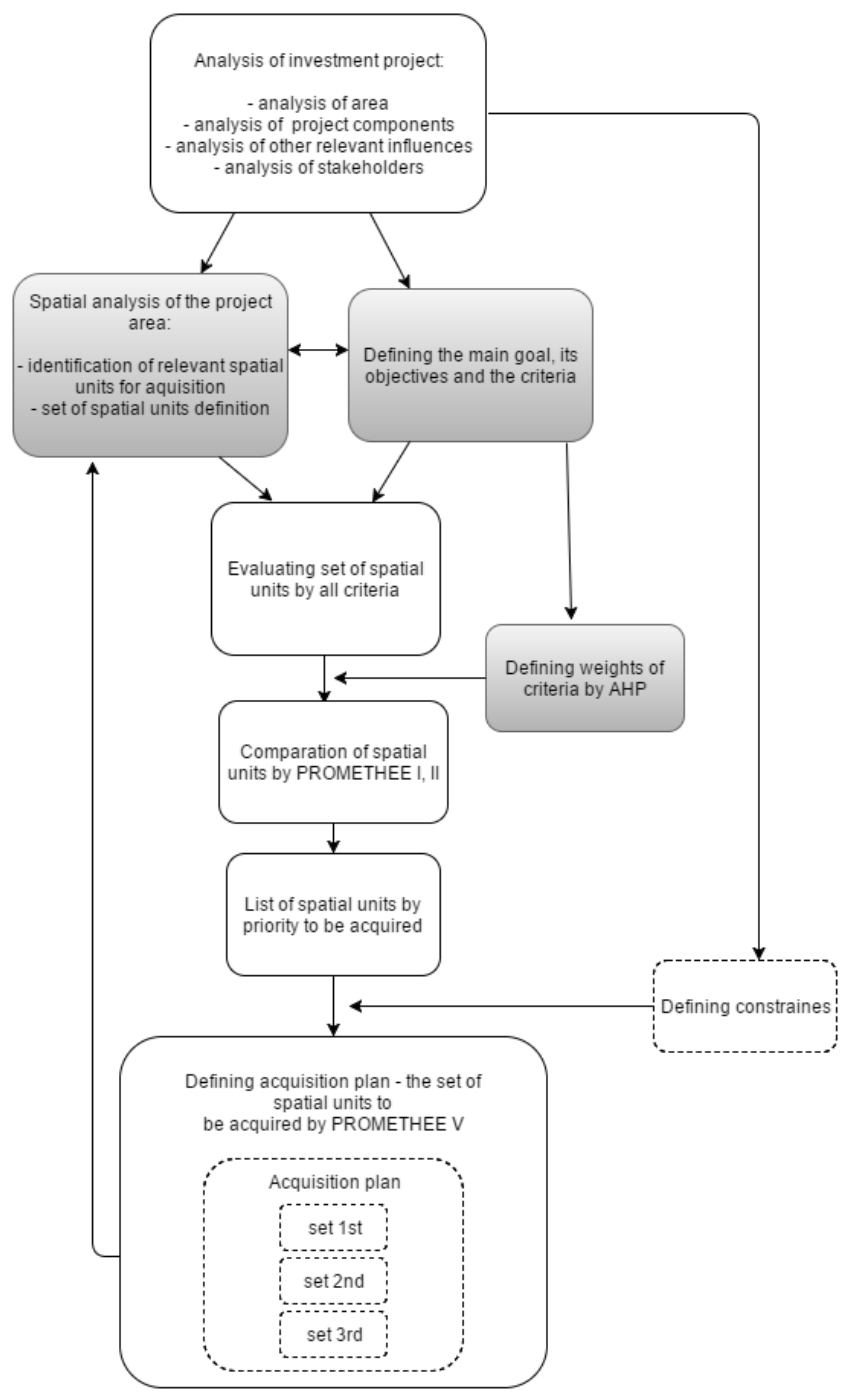

Figure 1: Concept for acquisition planning for realization of the University Campus Project in Split 
In validation of proposed DSC on "Campus project", GIS is used as a database and as a tool for planning of a land acquisition. Figure 2 shows three data layers folded in GIS: Urban Development Plan (UDP), digital cadastre parcel layer and layer of Campus measurement. Data are organized in the form of a table where are for each parcel defined the number of cadastral parcel, land registry number, proprietor of a parcel, landholder of a parcel, compatibility of the cadastre and land registry. Figure 2 shows subprojects area classified according to ownership relations of cadastral parcels which can be the ownership of the University of Split, the city of Split, private property or the government ownership. The first step in the land acquisition planning for realization of the University Campus project is analysis of investment project which includes analysis of spatial units area, analysis of project components, analysis of other relevant influences and analysis of stakeholders. The area of spatial units is determined by using geometric analysis, and the total number of spatial units in a particular ownership, the total area of the spatial units in a particular ownership, the proportion of the land area of particular owner in relation to the total land area of the Campus are determined by using statistical analysis. Analysis of project components (subproject) includes gathering all the documents and necessary data and also identification of relations and mutual dependences of project components to solve problem task. One of mayor activities within this step of DSC realisation is identification of relevant stakeholders. For the purpose of DSC validation stakeholders are identified and divided into four groups: investor (or its representative - project manager), government representative, private owners of parcels representatives and users' representatives. In the second step, two activities are conducting simultaneously.

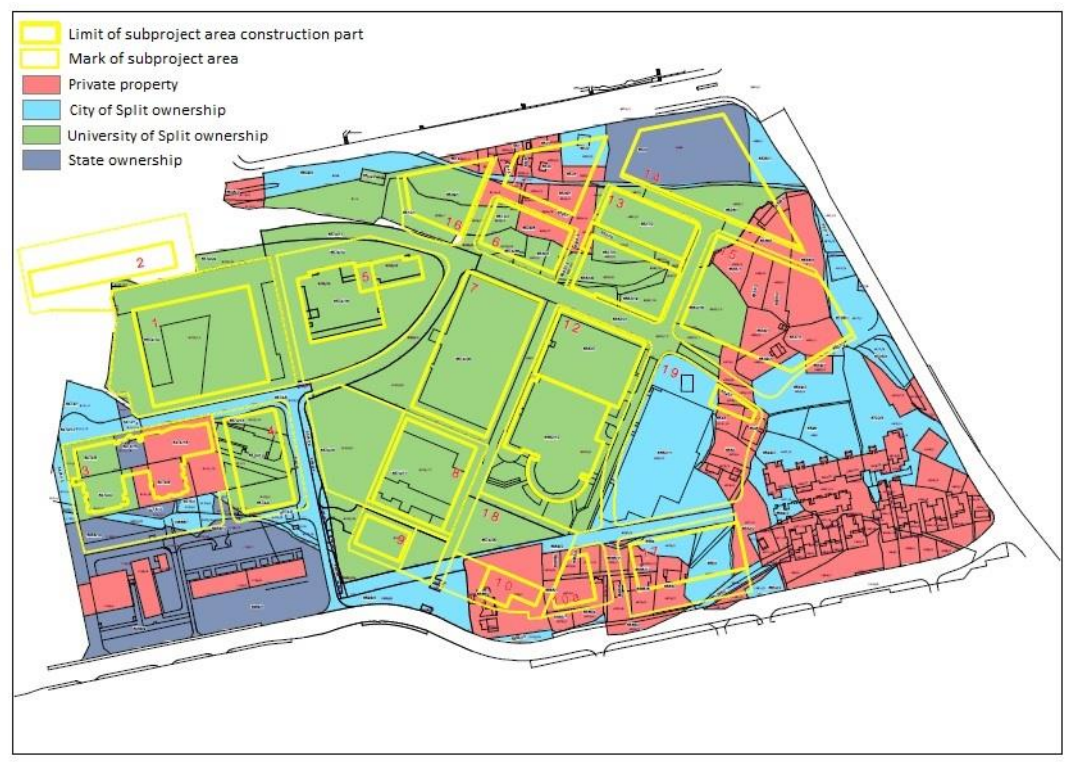

Figure 2: Map of Campus project with overview of spatial units that are taken into analysis classified according to ownership relations of cadastral parcels

First activity deals with identification of relevant spatial units for acquisition which includes determining the location of spatial units which are within validation project area and spatial 
units belonging to the particular subproject area. Subprojects are in fact the buildings in the function of University. Subprojects areas that will be examine are 4, 6, 9, 10, 10a, 13, 14 and 16 (Figure 2). Figure 2 shows area of Campus project with 38 spatial units (alternatives) which are identified within those subprojects areas (along with their property status).

Considering that the planning of construction projects from the investor point of view is mostly based on the economic aspects, during planning the construction of the Campus is necessary to consider the other relevant factors that influence on its development stages. Therefore, the goal hierarchy structure has been established. Designing the hierarchy structure the influential factors are identified and expressed in the criteria form. Other impacts/influences will be formulated through constraints which are introduced at a later stage of concept realization over PROMETHEE V method.

Second activity deals with above mentioned and begins with definition of the main goal - "Determining the plan of spatial units acquisition", its objectives and the criteria. All stakeholders are included in identification of the main goal, objectives and criteria. The main goal is divided into three supportive objectives. These objectives refer to maximization of construction aspects, maximization of investment aspects and maximization of social-real estate market aspects. Furthermore, objectives are divided into several subobjectives. All subobjectives from one group supports only their immediate superior objective and cannot be/doesn't need to be further divided. These subobjectives represent criteria which together with all abovementioned objectives and the main goal constitute the hierarchical structure in a form of a goal tree. The hierarchical structure designed for concept validation is shown in Figure 3 and its detailed explanation is presented below. Figure 3 shows the goal tree with three objectives and twelve subobjectives/criteria (C1-C12). Construction aspects are introduced through criteria from $\mathrm{C} 1$ to $\mathrm{C} 3$, investment aspects through criteria from $\mathrm{C} 4$ to C10, and socio-real estate market aspects through criteria from C10 to C12.

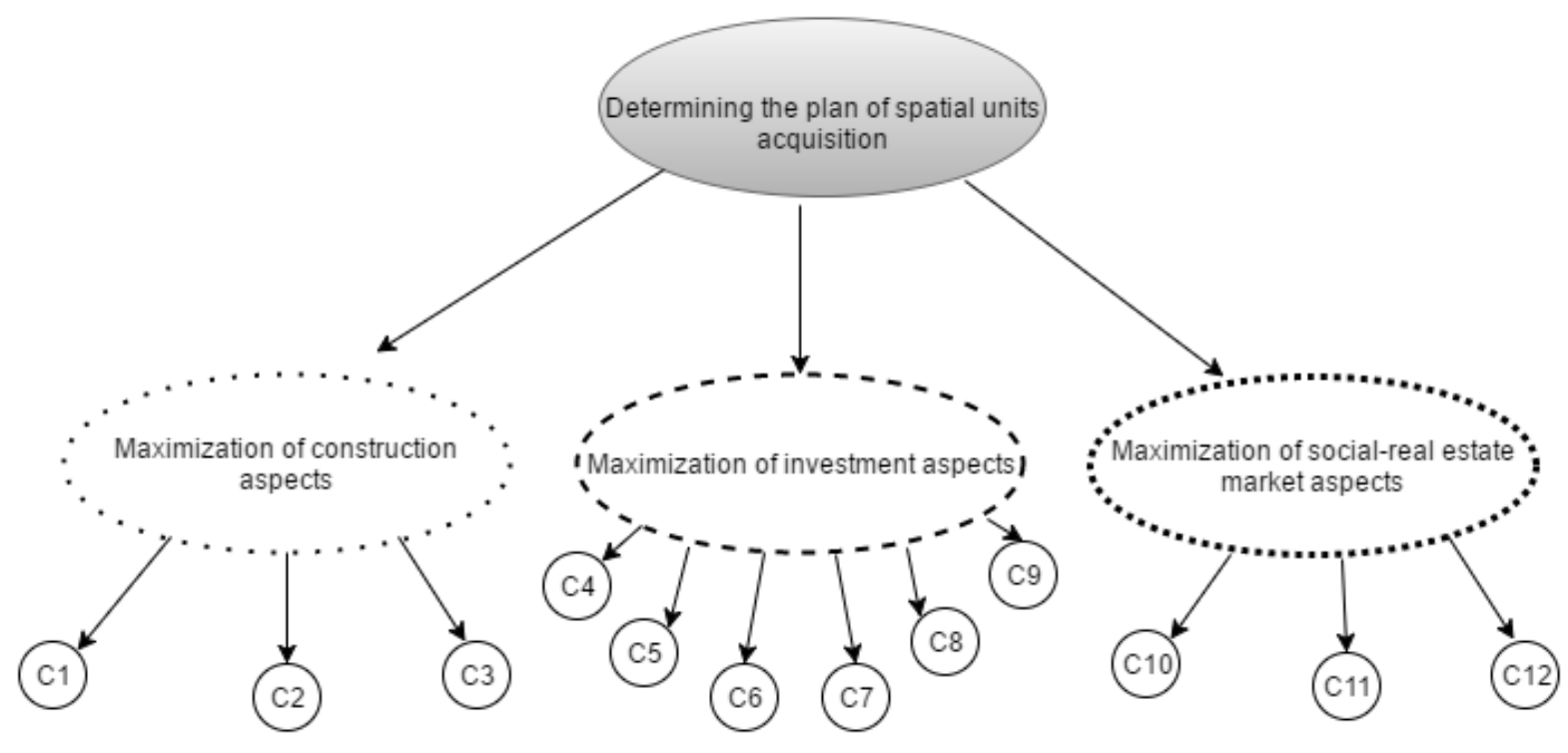

Figure 3: Goal hierarchy structure 
Table 1 shows the list of criteria, description of evaluation technique for each criterion, as well as the way of formatting the preference for each of the criteria (its preference function). Number of criteria that requires a minimum is seven, while maximum was searched for five criteria. V - Shape function of preferences is prevailing and it is used by 10 criteria. U-Shape functions are used for a 2 criteria.

\begin{tabular}{|c|c|c|c|c|}
\hline \multirow{2}{*}{$\begin{array}{c}\text { Criteria } \\
\text { label }\end{array}$} & \multirow{2}{*}{ Criteria name } & \multirow{2}{*}{$\begin{array}{l}\text { Short description of criteria and of technique } \\
\text { for evaluation of investment solutions }\end{array}$} & \multicolumn{2}{|c|}{ Preference } \\
\hline & & & $\min / \max$ & function \\
\hline C1 & Constructability & $\begin{array}{c}\text { Expert assessment - grading } 1 \text { (worst) }-10 \\
\text { (best) }\end{array}$ & Max & V-shape \\
\hline $\mathrm{C} 2$ & $\begin{array}{l}\text { The time required } \\
\text { for construction }\end{array}$ & $\begin{array}{c}\text { Expected duration of construction in } \\
\text { accordance to dynamic plan and to bill of } \\
\text { quantities - days }\end{array}$ & Min & V-shape \\
\hline C3 & $\begin{array}{l}\text { The time required } \\
\text { to obtain building } \\
\text { permits }\end{array}$ & Expert assessment of expected duration - days & Min & V-shape \\
\hline $\mathrm{C} 4$ & Construction cost & Expressed in EUR & Min & V-shape \\
\hline C5 & $\begin{array}{l}\text { Costs of land } \\
\text { acquisition }\end{array}$ & $\begin{array}{c}\text { The amount includes the cost of land } \\
\text { acquisition and other related costs - in EUR } \\
\text { per spatial units }\end{array}$ & Min & V-shape \\
\hline C6 & $\begin{array}{l}\text { Utility contribution } \\
\text { cost }\end{array}$ & Expressed in EUR & Min & V-shape \\
\hline $\mathrm{C} 7$ & $\begin{array}{l}\text { The integrity of } \\
\text { subproject area }\end{array}$ & $\begin{array}{c}\text { It is determined as share of evaluated spatial } \\
\text { unit area within total area of all spatial units } \\
\text { who need to be acquired in single subproject } \\
\text { area. It's expressed in } \% \text {. }\end{array}$ & $\operatorname{Max}$ & V-shape \\
\hline $\mathrm{C} 8$ & $\begin{array}{l}\text { Area od spatial } \\
\text { units }\end{array}$ & $\begin{array}{l}\text { It's determined as the area of spatial unit and } \\
\text { it's expressed in } \mathrm{m}^{2}\end{array}$ & Min & V-shape \\
\hline C9 & $\begin{array}{c}\text { Number of required } \\
\text { neighbouring } \\
\text { spatial units } \\
\end{array}$ & $\begin{array}{l}\text { Number of neighbouring spatial units which } \\
\text { need to be acquired for the formation of } \\
\text { construction parcel for an subproject }\end{array}$ & Min & V-shape \\
\hline C10 & $\begin{array}{l}\text { Owner interest for } \\
\text { sale }\end{array}$ & $\begin{array}{l}\text { It is determined whether the seller is } \\
\text { expressed interest in spatial unit selling: } \\
\text { if it is expressed interest in selling - } 1 \text {; if it is } \\
\text { not expressed interest in selling - } 0\end{array}$ & $\operatorname{Max}$ & Usual \\
\hline C11 & Investor interest & $\begin{array}{l}\text { It is determined level of the investor interest } \\
\text { in buying spatial unit: } \\
\text { level of investor interest in buying - from } 1 \\
\text { to } 10\end{array}$ & Max & V-shape \\
\hline
\end{tabular}




\begin{tabular}{|c|c|c|c|c|}
\hline C12 & $\begin{array}{c}\text { Integration into } \\
\text { spatial plans }\end{array}$ & $\begin{array}{l}\text { It is determined whether the object is } \\
\text { recorded into a spatial plans (e.g. city GUP) } \\
\text { or not (meaning it needs to be integrated) - } \\
\text { expressed as follows: if it is recorded - } 1 \text {; if } \\
\text { not recorded - } 0\end{array}$ & Max & Usual \\
\hline
\end{tabular}

Table 1: Criteria name and short description

The next step is the formation of decisions matrix (Table 2) which contains the evaluation results of all alternatives (38 spatial units) according to all criteria.

\begin{tabular}{|c|c|c|c|c|c|c|c|c|c|c|c|c|}
\hline $\begin{array}{l}\underset{\text { Criteria }}{\longrightarrow} \\
\downarrow_{\text {Investment }} \\
\text { solutions } \\
\end{array}$ & C1 & $\mathrm{C} 2$ & C3 & $\mathrm{C} 4$ & C5 & C6 & $\mathrm{C} 7$ & C8 & C9 & C10 & C11 & $\mathrm{C} 12$ \\
\hline $4(6574 / 46)$ & 9 & 550 & 380 & 5900000 & 0 & 0 & 70,57 & 578 & 7 & 1 & 9 & 1 \\
\hline $4(6574 / 43)$ & 9 & 550 & 380 & 5900000 & 0 & 0 & 13,92 & 114 & 7 & 1 & 9 & 1 \\
\hline $4(13666 / 11)$ & 9 & 550 & 380 & 5900000 & 0 & 0 & 5,98 & 49 & 7 & 1 & 9 & 1 \\
\hline $4(6574 / 44)$ & 9 & 550 & 380 & 5900000 & 0 & 0 & 2,44 & 20 & 7 & 1 & 9 & 1 \\
\hline $4(13666 / 10)$ & 9 & 550 & 380 & 5900000 & 0 & 0 & 1,10 & 9 & 7 & 1 & 9 & 1 \\
\hline $4(6576 / 3)$ & 9 & 550 & 380 & 5900000 & 0 & 0 & 0,61 & 5 & 7 & 1 & 9 & 1 \\
\hline $4(6576 / 4)$ & 9 & 550 & 380 & 5900000 & 0 & 0 & 3,91 & 32 & 7 & 1 & 9 & 1 \\
\hline $4(6458 / 16)$ & 9 & 550 & 380 & 5900000 & 0 & 0 & 1,47 & 12 & 7 & 1 & 9 & 1 \\
\hline $6(6528 / 6)$ & 6 & 565 & 740 & 4800000 & 326400 & 27900 & 100,00 & 816 & 0 & 1 & 8 & 1 \\
\hline $9(6568 / 2)$ & 10 & 540 & 370 & 1800000 & 0 & 34400 & 91,32 & 263 & 1 & 1 & 10 & 1 \\
\hline $9(6598 / 3)$ & 10 & 540 & 370 & 1800000 & 0 & 34400 & 8,68 & 25 & 1 & 1 & 10 & 1 \\
\hline $10(6568 / 3)$ & 10 & 350 & 1100 & 1700000 & 0 & 73000 & 6,01 & 134 & 3 & 1 & 5 & 0 \\
\hline $10(6598 / 3)$ & 10 & 350 & 1100 & 1700000 & 0 & 73000 & 14,22 & 317 & 3 & 1 & 5 & 0 \\
\hline $10(6566 / 2)$ & 10 & 350 & 1100 & 1700000 & 1038600 & 73000 & 77,62 & 1731 & 3 & 1 & 5 & 0 \\
\hline $10(6565 / 1)$ & 10 & 350 & 1100 & 1700000 & 12000 & 73000 & 2,15 & 48 & 3 & 1 & 5 & 0 \\
\hline $10 \mathrm{a}(6565 / 3)$ & 9 & 400 & 1835 & 1880000 & 14800 & 118500 & 1,94 & 37 & 10 & 0 & 1 & 0 \\
\hline $10 \mathrm{a}(6565 / 4)$ & 9 & 400 & 1835 & 1880000 & 8000 & 118500 & 1,05 & 20 & 10 & 0 & 1 & 0 \\
\hline $10 \mathrm{a}(6565 / 1)$ & 9 & 400 & 1835 & 1880000 & 570000 & 118500 & 49,71 & 950 & 10 & 0 & 1 & 0 \\
\hline $10 \mathrm{a}(6565 / 8)$ & 9 & 400 & 1835 & 1880000 & 800 & 118500 & 0,10 & 2 & 10 & 0 & 1 & 0 \\
\hline $10 \mathrm{a}(6565 / 13)$ & 9 & 400 & 1835 & 1880000 & 45600 & 118500 & 5,97 & 114 & 10 & 0 & 1 & 0 \\
\hline $10 \mathrm{a}(6565 / 9)$ & 9 & 400 & 1835 & 1880000 & 92800 & 118500 & 12,14 & 232 & 10 & 0 & 1 & 0 \\
\hline $10 \mathrm{a}(6565 / 10)$ & 9 & 400 & 1835 & 1880000 & 129600 & 118500 & 16,95 & 324 & 10 & 0 & 1 & 0 \\
\hline $10 \mathrm{a}(6565 / 11)$ & 9 & 400 & 1835 & 1880000 & 37200 & 118500 & 4,87 & 93 & 10 & 0 & 1 & 0 \\
\hline 10a $(6565 / 14)$ & 9 & 400 & 1835 & 1880000 & 26800 & 118500 & 3,51 & 67 & 10 & 0 & 1 & 0 \\
\hline
\end{tabular}


GIS-based Decision Support Concept to planning of land acquisition for realization of Urban Public Projects 19

\begin{tabular}{|c|c|c|c|c|c|c|c|c|c|c|c|c|}
\hline $10 \mathrm{a}(6565 / 5)$ & 9 & 400 & 1835 & 1880000 & 22800 & 118500 & 2,98 & 57 & 10 & 0 & 1 & 0 \\
\hline $10 \mathrm{a}(6568 / 2)$ & 9 & 400 & 1835 & 1880000 & 0 & 118500 & 0,78 & 15 & 10 & 0 & 1 & 0 \\
\hline $13(6528 / 5)$ & 8 & 935 & 0 & 4352000 & 8750 & 35200 & 25,93 & 35 & 1 & 1 & 10 & 1 \\
\hline $13(6528 / 4)$ & 8 & 935 & 0 & 4352000 & 25000 & 35200 & 74,07 & 100 & 1 & 1 & 10 & 1 \\
\hline $14(6524)$ & 5 & 730 & 1100 & 12900000 & 0 & 38400 & 78,56 & 4060 & 5 & 0 & 4 & 0 \\
\hline $14(6525 / 1)$ & 5 & 730 & 1100 & 12900000 & 0 & 38400 & 1,93 & 100 & 5 & 0 & 4 & 0 \\
\hline $14(13663 / 4)$ & 5 & 730 & 1100 & 12900000 & 0 & 38400 & 4,49 & 232 & 5 & 0 & 4 & 0 \\
\hline $14(6536 / 2)$ & 5 & 730 & 1100 & 12900000 & 133800 & 38400 & 4,32 & 223 & 5 & 0 & 4 & 0 \\
\hline $14(6536 / 1)$ & 5 & 730 & 1100 & 12900000 & 29220 & 38400 & 9,42 & 487 & 5 & 0 & 4 & 0 \\
\hline $14(6536 / 3)$ & 5 & 730 & 1100 & 12900000 & 26400 & 38400 & 1,28 & 66 & 5 & 0 & 4 & 0 \\
\hline $16(13663 / 1)$ & 5 & 750 & 1110 & 2800000 & 0 & 0 & 29,10 & 78 & 3 & 0 & 7 & 0 \\
\hline $16(6514)$ & 5 & 750 & 1110 & 2800000 & 11493 & 0 & 28,73 & 77 & 3 & 0 & 7 & 0 \\
\hline $16(6515 / 3)$ & 5 & 750 & 1110 & 2800000 & 16418 & 0 & 41,04 & 110 & 3 & 0 & 7 & 0 \\
\hline $16(6515 / 2)$ & 5 & 750 & 1110 & 2800000 & 672 & 0 & 1,12 & 3 & 3 & 0 & 7 & 0 \\
\hline
\end{tabular}

Table 2: Decision matrix

Using AHP (Analytic Hierarchy Processing) method and in accordance with both established goal tree and the attitudes of stakeholders, criteria importance (weights for each criterion) is provided. Multicriteria decision - making is supported by several strategies, also known as scenarios. Taking several preliminary scenarios (in this case four scenarios - one scenario for each group of stakeholders), the compromise scenario (fifth scenario) is defined, and it is used for comparison/ranking of 38 spatial units. That fifth/final scenario is defined as a set of compromise criteria weights, each of which is the average of the preliminary weights for the same criterion over all preliminary scenarios [9]. Although the geometric mean is preferred, in this case the arithmetic mean is used because of the stakeholders' preference for the arithmetic mean during their sessions. Weight of each criterion is expressed by its percentage share in the total mass of all the criteria that should always be $100 \%$ as it is shown in Table 3 .

\begin{tabular}{|c|c|c|c|c|c|c|}
\hline \multirow[b]{2}{*}{$\begin{array}{c}\text { Criteria } \\
\text { labels }\end{array}$} & \multirow[b]{2}{*}{ Criteria names } & \multicolumn{5}{|c|}{ Criteria weights } \\
\hline & & Scenario 1 & Scenario 2 & Scenario 3 & Scenario 4 & $\begin{array}{c}\text { Scenario } \\
5\end{array}$ \\
\hline $\mathrm{C} 1$ & Constructability & 6,42 & 7,82 & 4,29 & 1,02 & 4,89 \\
\hline $\mathrm{C} 2$ & $\begin{array}{l}\text { The time required for } \\
\text { construction }\end{array}$ & 6,77 & 8,54 & 5,34 & 2,20 & 5,71 \\
\hline C3 & $\begin{array}{c}\text { The time required to obtain } \\
\text { building permits }\end{array}$ & 6,81 & 8,64 & 5,37 & 1,78 & 5,65 \\
\hline $\mathrm{C} 4$ & Construction cost & 8,91 & 4,73 & 2,00 & 2,85 & 4,62 \\
\hline $\mathrm{C} 5$ & Costs of land acquisition & 8,89 & 4,62 & 3,51 & 2,43 & 4,86 \\
\hline C6 & Utility contribution cost & 8,71 & 4,58 & 2,12 & 2,63 & 4,51 \\
\hline $\mathrm{C} 7$ & The integrity of spatial units & 8,48 & 3,89 & 2,68 & 2,59 & 4,41 \\
\hline
\end{tabular}




\begin{tabular}{|c|c|c|c|c|c|c|}
\multicolumn{7}{|c|}{ Jelena Kilić, Nikša Jajac and Ivan Marović } \\
\hline C8 & Area od spatial units & 8,53 & 3,92 & 2,59 & 2,28 & $\mathbf{4 , 3 3}$ \\
\hline C9 & $\begin{array}{c}\text { Number of required } \\
\text { neighbouring spatial units }\end{array}$ & 6,48 & 3,26 & 2,10 & 2,22 & $\mathbf{3 , 5 2}$ \\
\hline C10 & Owner interest for sale & 10,21 & 16,47 & 26,32 & 25,92 & $\mathbf{1 9 , 7 3}$ \\
\hline C11 & Investor interest & 9,89 & 16,59 & 25,98 & 26,13 & $\mathbf{1 9 , 6 5}$ \\
\hline C12 & Integration into spatial plans & 9,90 & 16,94 & 17,70 & 27,95 & $\mathbf{1 8 , 1 2}$ \\
\hline
\end{tabular}

Table 3: Criteria weights for five scenarios

After determination of decision matrix and definition of compromise criteria weights (fifth scenario) as well as other relevant characteristics of criteria (preference functions, $\min / \max , . .$. ) comparison of 38 spatial units is conducted with the aid of software Visual PROMETHEE [8]. Multicriteria data were processed using multicriteria method PROMETHEE II and complete ranking (according to compromised scenario) was generated as it is shown in Figure 4.

\begin{tabular}{|c|c|c|c|c|c|}
\hline Rank & $\begin{array}{c}\text { Spatial } \\
\text { unit }\end{array}$ & $\begin{array}{l}\text { Net flow } \\
(\Phi)\end{array}$ & Rank & $\begin{array}{c}\text { Spatial } \\
\text { unit }\end{array}$ & $\begin{array}{l}\text { Net flow } \\
(\Phi)\end{array}$ \\
\hline 1 & $9(6568 / 2)$ & 0,4548 & 20 & $16(6514)$ & $-0,1273$ \\
\hline 2 & $9(6598 / 3)$ & 0,4199 & 21 & $\begin{array}{c}16 \\
(6515 / 2)\end{array}$ & $-0,1381$ \\
\hline 3 & $\begin{array}{c}13 \\
(6528 / 4)\end{array}$ & 0,372 & 22 & $\begin{array}{c}14 \\
(6525 / 1)\end{array}$ & $-0,2104$ \\
\hline 4 & $\begin{array}{c}4 \\
(6574 / 46)\end{array}$ & 0,3577 & 23 & $\begin{array}{c}14 \\
(13663 / 4)\end{array}$ & $-0,2107$ \\
\hline 5 & $\begin{array}{c}13 \\
(6528 / 5)\end{array}$ & 0,3523 & 24 & $\begin{array}{c}14 \\
(6536 / 3)\end{array}$ & $-0,2126$ \\
\hline 6 & $\begin{array}{c}4 \\
(6574 / 43) \\
\end{array}$ & 0,3371 & 25 & $\begin{array}{c}14 \\
(6536 / 1) \\
\end{array}$ & $-0,2138$ \\
\hline 7 & $\begin{array}{c}4 \\
(13666 / 11)\end{array}$ & 0,3342 & 26 & $14(6524)$ & $-0,219$ \\
\hline 8 & $4(6576 / 4)$ & 0,3334 & 27 & $\begin{array}{c}14 \\
(6536 / 2)\end{array}$ & $-0,2224$ \\
\hline 9 & $\begin{array}{c}4 \\
(6574 / 44)\end{array}$ & 0,3329 & 28 & $\begin{array}{c}10 a \\
(6568 / 2)\end{array}$ & $-0,2827$ \\
\hline 10 & $\begin{array}{c}4 \\
(6458 / 16)\end{array}$ & 0,3325 & 29 & $\begin{array}{c}10 \mathrm{a} \\
(6565 / 8)\end{array}$ & $-0,2829$ \\
\hline 11 & $\begin{array}{c}4 \\
(13666 / 10) \\
\end{array}$ & 0,3324 & 30 & $\begin{array}{c}10 \mathrm{a} \\
(6565 / 4)\end{array}$ & $-0,2833$ \\
\hline 12 & $4(6576 / 3)$ & 0,3322 & 31 & $\begin{array}{c}10 \mathrm{a} \\
(6565 / 3)\end{array}$ & $-0,2837$ \\
\hline 13 & $6(6528 / 6)$ & 0,3001 & 32 & $\begin{array}{c}10 \mathrm{a} \\
(6565 / 5)\end{array}$ & $-0,2841$ \\
\hline 14 & $\begin{array}{c}10 \\
(6566 / 2) \\
\end{array}$ & 0,0998 & 33 & $\begin{array}{c}10 \mathrm{a} \\
(6565 / 14)\end{array}$ & $-0,2844$ \\
\hline 15 & $\begin{array}{c}10 \\
(6598 / 3)\end{array}$ & 0,0957 & 34 & $\begin{array}{c}10 \mathrm{a} \\
(6565 / 11)\end{array}$ & $-0,2849$ \\
\hline 16 & 10 & 0,094 & 35 & $10 \mathrm{a}$ & $-0,2854$ \\
\hline
\end{tabular}


GIS-based Decision Support Concept to planning of land acquisition for realization of Urban Public Projects

\begin{tabular}{|c|c|c|c|c|c|}
\hline & $(6568 / 3)$ & & & $(6565 / 13)$ & \\
\hline 17 & $\begin{array}{c}10 \\
(6565 / 1)\end{array}$ & 0,0921 & 36 & $\begin{array}{c}10 \mathrm{a} \\
(6565 / 9)\end{array}$ & $-0,288$ \\
\hline 18 & $\begin{array}{c}16 \\
(6515 / 3)\end{array}$ & $-0,1225$ & 37 & $\begin{array}{c}10 \mathrm{a} \\
(6565 / 10)\end{array}$ & $-0,2901$ \\
\hline 19 & $\begin{array}{c}16 \\
(13663 / 1)\end{array}$ & $-0,1262$ & 38 & $\begin{array}{c}10 \mathrm{a} \\
(6565 / 1)\end{array}$ & $-0,3207$ \\
\hline
\end{tabular}

Table 4: Net flow results-complete ranking (PROMETHEE II method) of 38 spatial units by compromise (fifth) scenario

The complete ranking and net flow $(\Phi)$ for compromise (fifth) scenario is shown in Table 4, and the graphical presentation of net flow results in Figure 4.

From results in Table 4 and Figure 4 it can be seen that spatial unit $9(6568 / 2)$ has the highest net flow $\Phi=0,4548$, and spatial unit 10a (6565/1) the lowest $\Phi=-0,3207$.

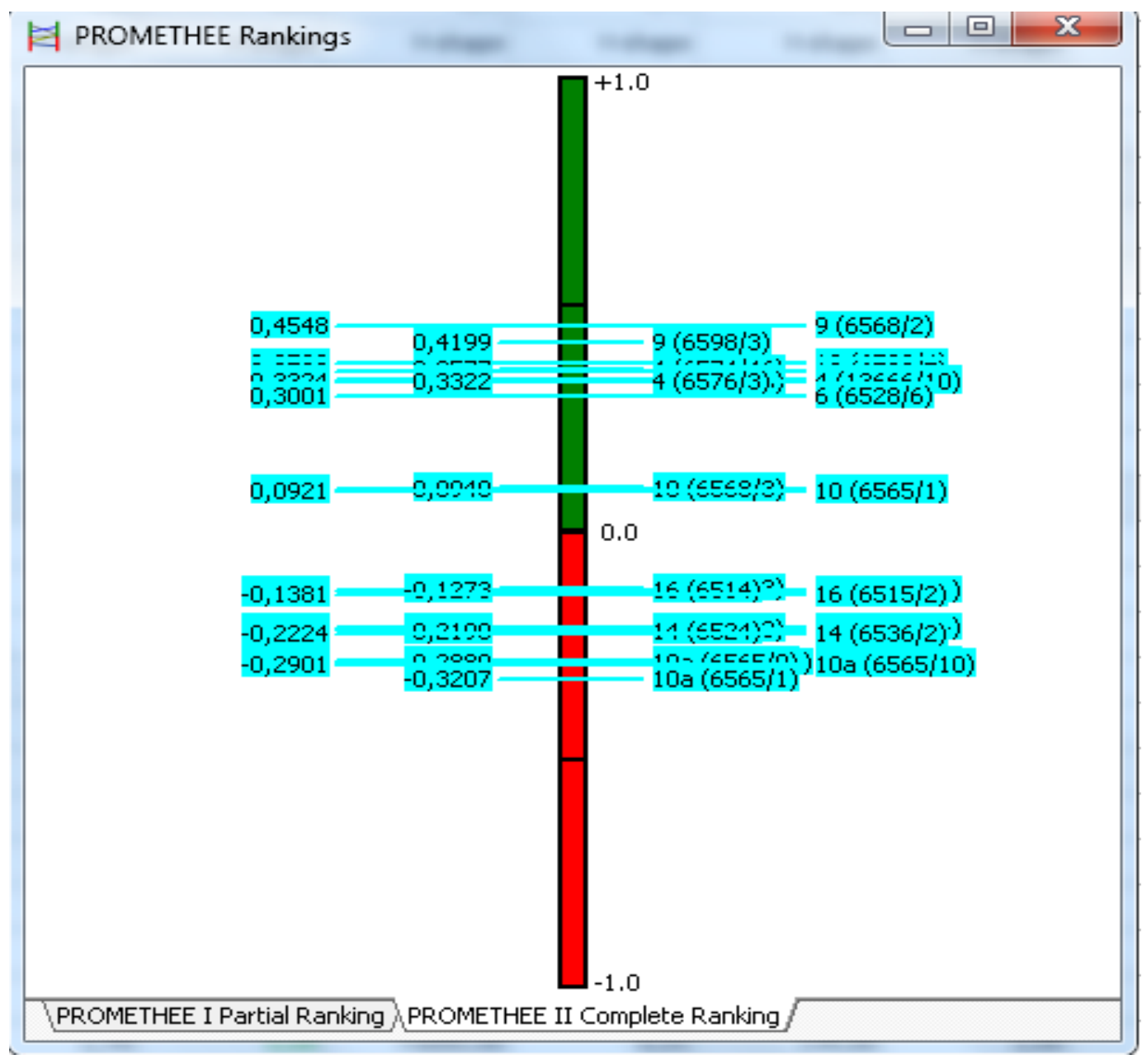

Figure 4: Graphical presentation of net flow results and PROMETHEE II complete ranking of 38 spatial units by compromise (fifth) scenario

Differences between analyzed spatial units are quite small and there aren't large deviations between them but their division into two groups is obvious. 
Next step is constraints defining and it is conducted only by investor. These constraints are defined by $0-1$ integer linear programming (as a set of linear equations and/or inequalities). Only one constraint within this set is related to the available financial resources $(360150,00$ EUR) for next investment cycle. All other constrains are related to functional and spatial aspects of analyzed problem. Three non-financial constraints are as follows: 1st - no more than eight spatial units from the area of subproject 4, 2nd - no more than three spatial units from areas of subprojects 9, 10 and 10a, and 3rd - no more than three spatial units from areas of subprojects 6, 13 and 14, 16. PROMETHEE V method is used for introduction of these 4 constraints into investment planning process only by investor. The goal function and above specified constraints which are used are shown below:

The final goal function:

$$
\begin{aligned}
& \max \sum_{j=1}^{38} \Phi_{j} x_{j}, j=1,2,3, \ldots, 38 ; \max \left\{0,4548 x_{1}+0,4199 x_{2}+0,372 x_{3}\right. \\
& +0,3577 x_{4}+0,3523 x_{5}+0,3371 x_{6}+0,3342 x_{7}+0,3334 x_{8}+0,3329 x_{9} \\
& +0,3325 x_{10}+0,3324 x_{11}+0,3322 x_{12}+0,3001 x_{13}+0,0998 x_{14} \\
& +0,0957 x_{15}+0,094 x_{16}+0,0921 x_{17}-0,1225 x_{18}-0,1262 x_{19} \\
& -0,1273 x_{20}-0,1381 x_{21}-0,2104 x_{22}-0,2107 x_{23}-0,2126 x_{24} \\
& -0,2138 x_{25}-0,219 x_{26}-0,2224 x_{27}-0,2827 x_{28}-0,2829 x_{29} \\
& -0,2833 x_{30}-0,2837 x_{31}-0,2841 x_{32}-0,2844 x_{33}-0,2849 x_{34} \\
& \left.-0,2854 x_{35}-0,288 x_{36}-0,2901 x_{37}-0,3207 x_{38}\right\}
\end{aligned}
$$

Non-financial constraints:

$$
\begin{gathered}
x_{1}+x_{2}+x_{3}+x_{4}+x_{5}+x_{6}+x_{7}+x_{8} \leq 8 \\
x_{12}+x_{13}+x_{14}+x_{15}+x_{16}+x_{17}+x_{18}+x_{19}+x_{20}+x_{21}+x_{22}+x_{23}+x_{24}+x_{25}+x_{26} \leq 3 \\
x_{9}+x_{10}+x_{11}+x_{27}+x_{28}+x_{29}+x_{30}+x_{31}+x_{32}+x_{33}+x_{34}+x_{35}+x_{36}+x_{37}+x_{38} \leq 3 \\
0,3329 x_{9}+0,0998 x_{14}+0,0957 x_{15}+0,094 x_{16}+0,0921 x_{17}-0,1225 x_{18} \\
-0,1262 x_{19}-0,1273 x_{20}-0,1381 x_{21}-0,2104 x_{22}-0,2107 x_{23}-0,2126 x_{24} \\
-0,2138 x_{25}-0,2224 x_{27}-0,2827 x_{28}-0,2841 x_{32}-0,2844 x_{33}-0,2849 x_{34} \\
-0,288 x_{36}-0,2901 x_{37}-0,3207 x_{38} \leq 360150
\end{gathered}
$$

\begin{tabular}{|c|c|}
\hline \multicolumn{2}{|c|}{ The first set of spatial units for acquisition } \\
\hline $6568 / 2$ & $6576 / 4$ \\
\hline $6598 / 3$ & $6574 / 44$ \\
\hline $6528 / 4$ & $6458 / 16$ \\
\hline $6574 / 46$ & $13666 / 10$ \\
\hline $6528 / 5$ & $6576 / 3$ \\
\hline $6574 / 43$ & $6528 / 6$ \\
\hline $13666 / 11$ & \\
\hline
\end{tabular}

Table 5: PROMETHEE V results - 1st set of the acquisition plan 
According to the results of PROMETHEE $\mathrm{V}$ method presented within Table 5, 13 of 38 analysed spatial units should be included in the investment plan for the next investment cycle. Repeating usage of DSC for each following investment cycle (until all spatial units are acquired) is recommended due constant changing of Campus project environment. Each time a new set of spatial units for acquisition will be determined and it stands for one activity within the acquisition plan.

\section{Conclusion}

In this paper is described research on the establishment of GIS-based Decision Support Concept (DSC) to planning of land acquisition for realization of urban public projects that is validated as useful to project managers. It supports identification, selection and priority ranking of spatial units (cadastral parcels or their segments) whose acquisition enables further realization of commenced project. Most of the problems encountered when solving poorly structured tasks such as planning land acquisition for realization of urban public projects can be overcome by using this approach, proposed DSC. Planning process of land acquisition is improved by the application of the new methodology and project managerial approach that is based on the multicriteria analyses. Advantages of this approach are numerous, and are reflected in retrieval of all available data and information necessary for the project management and their processing which has created a good basis for decision making. Similarly, the advantage is also evident by the inclusion of all necessary stakeholders in the decision-making process thus increasing the quality of the planning process in finding a compromise solution to the specific problem. According to the all presented in this paper, the goal of the research has been achieved which means that the useful concept of decision support for the planning of land acquisition has been established. By the construction of the urban public projects, consisted of several subprojects which represent certain faculty buildings and buildings in the function of University, is particularly valuable in addition to the financial aspects which is an important factor that affects the speed of project implementation taking into account other significant impact that implicate the outcome of the investment project. Applying a family of PROMETHEE methods for priority ranking and AHP method for determining criteria weights it is possible to solve the problem taking into account the construction aspects, investment aspects and socio-real estate market aspects within which the project will be implemented.

\section{References}

[1] Brans, J. P., Mareschal, B. and Vincke, P. H. (1984). PROMETHEE: a New Family of Outranking Methods in Multicriteria Analysis. In Brans, J. P. (Ed.). OR'84 (pp. 477-490). Amsterdam: North Holland. 
[2] Jajac, N., Bilić, I. and Ajduk, A. (2012). Decision Support Concept to Management of Construction Projects - Problem of Construction Site Selection. Croatian Operational Research Review, 4, 235-247.

[3] Jajac, N., Knezić, S. and Marović, I. (2009). Decision support system to urban infrastructure maintenance management. Organization, technology and management in construction, 1(2), 72-79.

[4] Jajac, N., Marović, I. and Baučić, M. (2014). Decision support concept for managing the maintenance of city parking facilities. e-GFOS, 9, 60-69.

[5] Jajac, N., Marović, I. and Hanak, T. (2015). Decision Support to Management of Transportation Projects: Improvement of Urban Road Infrastructure Planning. Građevinar, 67(2), 131-141.

[6] Jajac, N., Rogulj, K. and Radnić, J. (2016). Selection of the Method for Rehabilitation of Historic Bridges - Decision Support Concept for Planning of Rehabilitation Projects. International Journal of Architectural Heritage, 11(2), 261-277.

[7] Jankowsky, P., Nyerges, T. L., Smith, A., Moore, T. J. and Horvath, E. (1997). Spatial group choice: a SDSS tool for collaborative spatial decision making. International Journal of Geographical Information Science, 11 (6), 577-602.

[8] Mareschal, B. (2011). Visual PROMETHEE http://www.prometheegaia.net/visualpromethee.html [Accessed 5/10/2016]

[9] Kennan, P. B. (2006.) Spatial Decision Support Systems: A coming of Age. Control and Cybernetics, 35, 9-27.

[10] Rayed, C. A. (2012). Using GIS for Modelling a Spatial DSS for Industrial Pollution in Egypt. American Journal of Geographic Information System, 1(4), 100-104.

[11] Saaty, T. L. (1980). The Analytic Hierarchy Process. New York: McGraw Hill. 